\title{
Differential Cyclic Voltammetry - a Novel Technique for Selective and Simultaneous Detection using Redox Cyling Based Sensors
}

\author{
M. Odijk, J. Wiedemair, M.J.J. van Megen, W. Olthuis, A. van den Berg \\ BIOS the Lab-on-a-Chip group \\ Mesa+ institute, University of Twente \\ Enschede, The Netherlands \\ m.odijk@utwente.nl
}

\begin{abstract}
Redox cycling (RC) is an effect that is used to amplify electrochemical signals. However, traditional techniques such as cyclic voltammetry (CV) do not provide clear insight for a mixture of multiple redox couples while $R C$ is applied. Thus, we have developed a new measurement technique which delivers electrochemical spectra of all reversible redox couples present based on concentrations and standard potentials. This technique has been named differential cyclic voltammetry (DCV).
\end{abstract}

We have fabricated micrometer-sized interdigitated electrode (IDE) sensors to conduct DCV measurements in mixtures of $1 \mathrm{mM}$ catechol and $4 \mathrm{mM}\left[\mathrm{Ru}\left(\mathrm{NH}_{3}\right)_{6}\right] \mathrm{Cl}_{3}$. To simulate the electrochemical behavior of these sensors we have also developed a finite element model (FEM) in Comsol ${ }^{\circledR}$. The experimental data corresponds to the calculated spectra obtained from simulations. Additionally, the measured spectra can be used to easily derive standard potentials and concentrations simultaneously and selectively.

\section{INTRODUCTION}

Redox cycling (RC) is an electrochemical detection method that can be utilized to determine redox active species in the presence of interfering compounds [1-5]. With this method it is even possible to achieve single molecule detection [6].

In most RC schemes a reversible redox couple is cycled between an oxidating and a reducing electrode. Each cycle between the two electrodes contributes to the measured current effectively amplifying the current in an (electro)chemical manner [7].

Most papers on $\mathrm{RC}$ make use of an interdigitated array electrode [8-22]. With such an electrode a $\mathrm{RC}$ amplification of up to $\sim 65$ times is reported in bulk [2]. An amplification of 100 times is reported for IDEs used in nanochannels [23]. Zevenbergen et al. [24] fabricated a device with two parallel, nanometer-spaced electrodes which resulted in an even higher $\mathrm{RC}$ amplification factor of $\sim 400$ times.

Using the same electrode structure as Zevenbergen et al., Wolfrum et al. [5] report cyclic voltammetry (CV) where only
265 molecules are involved. During scanning electrochemical microscopy (SECM) the so-called feedback mode uses the RC effect to amplify the current measured between a disk-shaped ultramicroelectrode and a (biased) substrate. Using this method Fan and Bard [6] report the detection of single molecule activity.

It is feasible to achieve selective detection using $\mathrm{RC}$ since only the current of cycling species is amplified. For example, it is shown that small amounts of catechol can be detected in presence of interfering species such as ascorbic acid [5]. Both ascorbic acid and catechol are oxidized easily, however only catechol forms a reversible redox couple with quinone. Therefore, only the current measured from catechol conversion is amplified by RC. Also, it is possible to obtain selective detection in a mixture of multiple reversible couples, if e.g. ferrocyanide and dopamine are both present in solution $[1,2]$. The key issue in the latter case is to apply appropriate potentials to both electrodes such that only dopamine is subjected to RC.

In publications reported so far one electrode is usually set to a fixed potential while the potential of the other electrode is controlled using CV. Data obtained this way is often not as conclusive as desired, since it is difficult to obtain direct information on the concentrations of the species present.

In this contribution we present a novel technique which we have named differential cyclic voltammetry (DCV). DCV is based on $\mathrm{RC}$, and delivers immediate information on all reversible redox species present within the solution. The resulting data resembles a differential pulse voltammogram (DPV) or the electrochemical equivalent of a mass spectrogram. On the $\mathrm{x}$-axis (unit: volt) peaks indicate the standard potential of a reversible redox couple, whereas on the $y$-axis (unit: ampere) the concentration of this couple is indicated. Compared to DPV DCV has the added benefit of more selectivity and a simpler potential waveform. We have tested this new technique both theoretically and practically using a finite element model and IDE sensors. 


\section{THEORY}

\section{A. Governing equations}

The basic governing equations used in the FEM model are the Nernst-Planck equation and the continuity equation. Diffusion is assumed as the only means of mass transport, which is valid if geometric dimensions are much larger than the Debye-length and sufficient excess supporting electrolyte is present. The resulting domain equation is as follows:

$$
\partial \mathrm{C}_{\mathrm{j}} / \partial \mathrm{t}=\mathrm{D}_{\mathrm{j}} \nabla^{2} \mathrm{C}_{\mathrm{j}}
$$

where $C_{j}$ is the concentration $\left(\mathrm{mol} / \mathrm{m}^{3}\right)$ and $\mathrm{D}_{\mathrm{j}}$ the diffusion coefficient $\left(\mathrm{m}^{2} / \mathrm{s}\right)$ of redox active species $\mathrm{j}$. For reversible redox reactions, the general chemical reaction is described by:

$$
\mathrm{O}+\mathrm{z} \cdot \mathrm{e}^{-} \leftrightarrow \mathrm{R}
$$

where $\mathrm{z}$ indicates the number of electrons involved during oxidation or reduction of a single electroactive species. The forward $\left(\mathrm{k}_{\mathrm{f}}\right.$, reduction) and backward $\left(\mathrm{k}_{\mathrm{b}}\right.$, oxidation) reaction rates $(\mathrm{m} / \mathrm{s})$ are described by the Butler-Volmer equations [7]:

$$
\begin{array}{r}
k_{f}=k_{s} \cdot \exp \left[-\alpha \cdot\left(E_{a p p l}-E^{\circ}\right) \cdot F /(R \cdot T)\right] \\
k_{b}=k_{s} \cdot \exp \left[(1-\alpha) \cdot\left(E_{a p p l}-E^{\circ}\right) \cdot F /(R \cdot T)\right]
\end{array}
$$

where $\mathrm{k}_{\mathrm{s}}$ is the standard rate constant, $\alpha$ the transfer coefficient, $\mathrm{E}^{\circ}$ the standard potential of the redox couple and $\mathrm{E}_{\text {appl }}$ the applied electrode potential. $\mathrm{F}, \mathrm{R}$, and $\mathrm{T}$ are the Faraday constant, the gas constant, and the temperature, respectively. For the second redox couple with a two electron transfer reaction it is assumed that one of the electrons transferred determines the overall reaction rate, thus $\mathrm{z}$ is not

\begin{tabular}{|c|c|c|}
\hline Parameter & Value & Unit \\
\hline F- Faraday constant & 96485 & {$[\mathrm{C} / \mathrm{mol}]$} \\
\hline $\mathrm{R}-$ Gas constant & 8.31 & {$[\mathrm{~J} / \mathrm{K}]$} \\
\hline $\mathrm{T}$-Temperature & 290 & {$[\mathrm{~K}]$} \\
\hline $\mathrm{D}_{10}-$ Diffusion coefficient, oxidized sp. 1 [25] & $7.5 \mathrm{E}-10$ & {$\left[\mathrm{~m}^{2} / \mathrm{s}\right]$} \\
\hline$D_{1 R}-$ Diffusion coefficient, reduced sp. 1 [25] & $7.5 \mathrm{E}-10$ & {$\left[\mathrm{~m}^{2} / \mathrm{s}\right]$} \\
\hline $\mathrm{D}_{2 \mathrm{O}}-$ - Diffusion coefficient, oxidized sp. $2[26]$ & $7.6 \mathrm{E}-10$ & {$\left[\mathrm{~m}^{2} / \mathrm{s}\right]$} \\
\hline $\mathrm{D}_{2 \mathrm{R}}-$ Diffusion coefficient, reduced sp. 2 [26] & $7.6 \mathrm{E}-10$ & {$\left[\mathrm{~m}^{2} / \mathrm{s}\right]$} \\
\hline $\mathrm{C}_{10}^{*}-$ Bulk concentration, oxidized sp. 1 & 4 & {$\left[\mathrm{~mol} / \mathrm{m}^{3}\right]$} \\
\hline $\mathrm{C}_{1 \mathrm{R}}^{*}-$ Bulk concentration, reduced sp. 1 & 0 & {$\left[\mathrm{~mol} / \mathrm{m}^{3}\right]$} \\
\hline $\mathrm{C}_{2 \mathrm{O}}^{*}-$ Bulk concentration, oxidized sp. 2 & 1 & {$\left[\mathrm{~mol} / \mathrm{m}^{3}\right]$} \\
\hline $\mathrm{C}_{2 \mathrm{R}}^{*}-$ Bulk concentration, reduced sp. 2 & 0 & {$\left[\mathrm{~mol} / \mathrm{m}^{3}\right]$} \\
\hline$\alpha_{1}-$ Transfer coefficient, redox couple 1 & 0.5 & \\
\hline $\mathrm{k}_{\mathrm{s} 1}-$ Rate constant, redox couple $1[27]$ & $3 \mathrm{E}-3$ & {$[\mathrm{~m} / \mathrm{s}]$} \\
\hline$\alpha_{2}-$ Transfer coefficient, redox couple 2 & 0.5 & \\
\hline $\mathrm{k}_{\mathrm{s} 2}-$ Rate constant, redox couple $2[28]$ & $4.65 \mathrm{E}-4$ & {$[\mathrm{~m} / \mathrm{s}]$} \\
\hline $\mathrm{E}_{1}^{\circ}-$ Standard potential, redox couple $1[25]$ & -0.16 & {$[\mathrm{~V}]$} \\
\hline $\mathrm{E}_{2}^{\circ}-$ Standard potential, redox couple $2[5]$ & 0.2 & [V] \\
\hline $\mathrm{v}-$ Scan rate & 50 & {$[\mathrm{mV} / \mathrm{s}]$} \\
\hline $\mathrm{z}_{1}-$ Number of electrons transferred per sp. 1 & 1 & \\
\hline$z_{2}-$ Number of electrons transferred per sp. 2 & 2 & \\
\hline
\end{tabular}
included in equations 3 and 4 [7]. Values and units of all parameters are listed in table 1.

TABLE I. PARAMETERS USED IN THE FEM MODEL

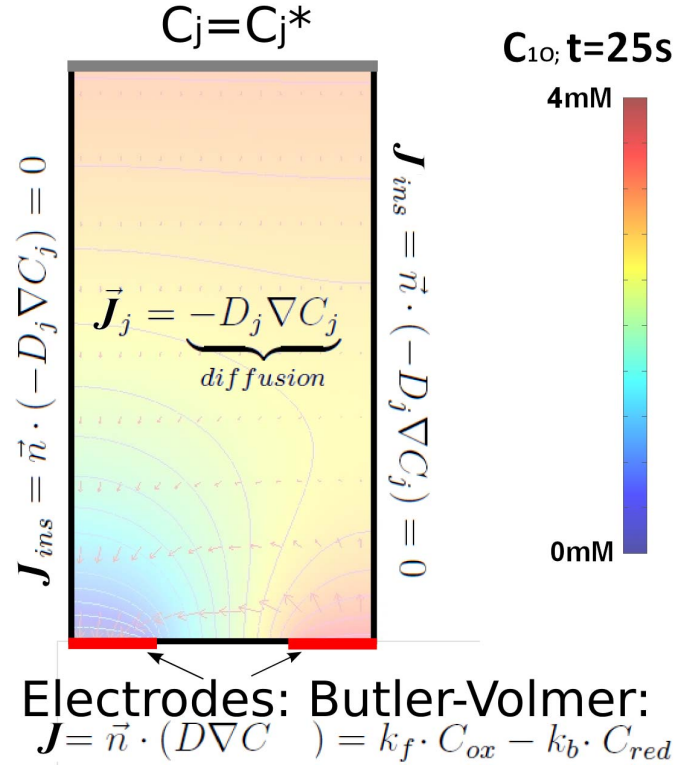

Figure 1. FEM model geometry. The different equations define the domain equations and boundary conditions used to define either flux (J) or concentration $\left(\mathrm{C}_{\mathrm{j}}\right)$. The background color indicates the concentration profile of oxidized species 1 at RC potentials.

Two reversible redox couples (sp.1 and sp.2) are used with standard potentials, diffusion coefficients, and rate constants matching $\mathrm{Ru}\left(\mathrm{NH}_{3}\right)_{6}$ and catechol respectively $[5,25,26,27$, 28].

\section{B. Geometric model}

The geometric model is depicted in figure 1. To minimize computing time and required computing memory only one finger pair of the IDE sensor is simulated. This model simplification is valid if the number of fingers is large compared to the amount of fingers at the edge of the IDE structure. The vertical walls of the model are set to symmetrical boundary conditions as described by the following (zero flux) boundary condition:

$$
-\mathrm{D}_{\mathrm{j}} \nabla \mathrm{C}_{\mathrm{j}}=0
$$

Due to symmetry considerations, the electrodes are $2 \mu \mathrm{m}$ wide in the model which is equivalent to a finger width of $4 \mu \mathrm{m}$ in reality. The gap width between the two electrodes is equal to $4 \mu \mathrm{m}$.

At a position far from the electrode surface concentrations are set to the initial bulk concentrations as listed in table 1 . To ensure a real bulk situation this position is estimated by:

$$
\mathrm{y}_{\text {top }}=\sqrt{ }\left(2 \cdot \mathrm{D}_{\max } \cdot \mathrm{t}_{\text {tot }}\right)
$$

where $\mathrm{y}_{\text {top }}$ is the vertical distance between the electrodes and the bulk boundary condition, $\mathrm{t}_{\text {tot }}$ the total simulation time and $\mathrm{D}_{\max }$ the fastest diffusion coefficient of all ions present. In this simulation the total simulated time was $66 \mathrm{~s}$, resulting in a 


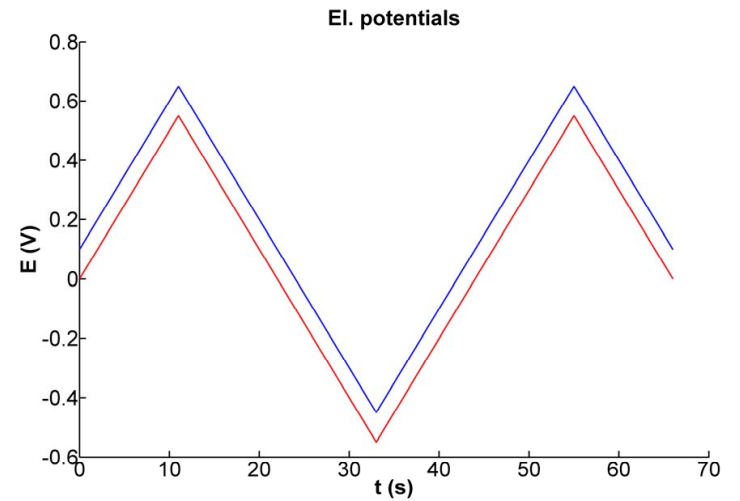

Figure 2. Potentials applied to both electrodes as used in the DCV technique. A fixed offset of, in this case $100 \mathrm{mV}$, is maintained.

distance of $317 \mu \mathrm{m}$ between the bulk condition boundary and the electrodes.

\section{Applied potentials}

The key point for using DCV is the application of appropriate potentials to both electrodes. These potentials are illustrated in figure 2 . The potential of one electrode is shown in red, and the potential waveform of the other electrode in blue. Between the two waveforms a fixed offset is maintained. The value of this offset is related to the peak width observed in the data obtained using DCV. The optimal offset for maximized resolution is related to the peak separation in conventional $\mathrm{CV}$, which is [7]:

$$
\Delta \mathrm{E}_{\mathrm{p}}=2.2 \cdot \mathrm{R} \cdot \mathrm{T} /(\mathrm{z} \cdot \mathrm{F})
$$
$57 \mathrm{mV}$.

For a single electron transfer reaction at $25^{\circ} \mathrm{C} \Delta \mathrm{E}_{\mathrm{p}}$ equals

\section{EXPERIMENTAL}

\section{A. Sensor fabrication}

The IDE sensors are fabricated using conventional lithography and lift-off processes. A 550nm layer of lift-off resist (LOR5a, Microchem) and $1.7 \mu \mathrm{m}$ of positive resist (OIR $907 / 17$, Fujifilm) is spun on a $500 \mu \mathrm{m}$ borofloat wafer followed by exposure and development for structure definition.

The electrodes are deposited by sputtering a $25 \mathrm{~nm}$ titanium adhesion layer and a 500nm gold layer. Excess metal is removed by lift-off in aceton. Afterwards, the wafer is diced into individual chips of $2 \times 5 \mathrm{~mm}$. For convenient handling the chips are glued to a printed circuit board (PCB) using Loctite ${ }^{\circledR}$ M-31CL ${ }^{\mathrm{TM}}$ Hysol ${ }^{\circledR}$. Electrical connections from the PCB to the IDE sensor on the chip are made using a wirebonder (Westbond). Finally, an additional layer of Hysol is added to shield the contact pads and wirebonds from the solution.

The resulting sensor is depicted in figure 3 . In the middle the entire sensor assembly is visible, in the upper left corner the individual chip and on the lower right corner a microscope image of the IDE sensor. Each individual finger is $557 \mu \mathrm{m}$

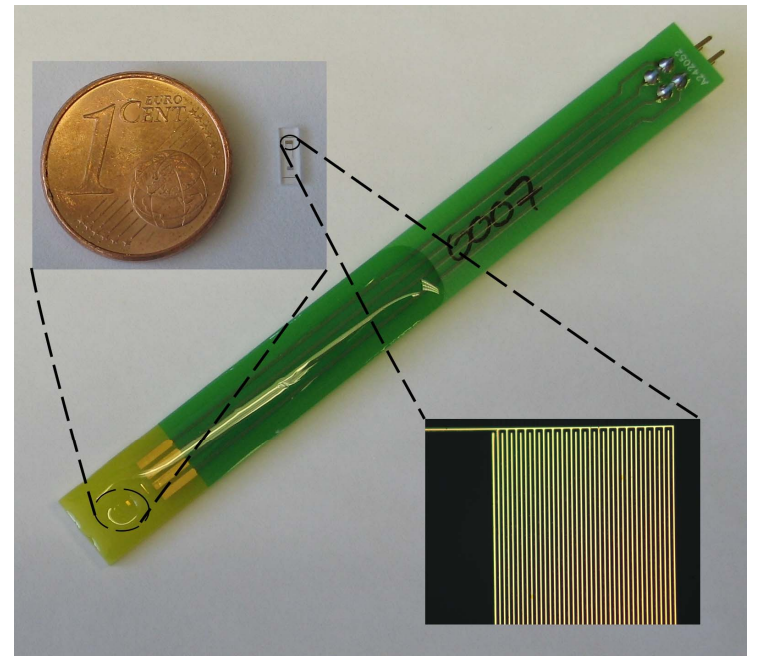

Figure 3. Photographs of the sensor glued on a PCB for easy handling (middle), and next to one euro cent (upper-left inset). Microscope image of the IDE sensor (lower-right inset). Each individual finger is $557 \mu \mathrm{m} \mathrm{x}$

$4 \mu \mathrm{m}(1 \mathrm{x} \mathrm{w})$ with a $4 \mu \mathrm{m}$ gap. The total IDE contains 20 finger pairs.

long and $4 \mu \mathrm{m}$ wide, with a $4 \mu \mathrm{m}$ gap in between. The total electrode height is $525 \mathrm{~nm}$, and the IDE sensor contains 20 finger pairs.

\section{B. Chemicals}

A solution of $4 \mathrm{mM}\left[\mathrm{Ru}\left(\mathrm{NH}_{3}\right)_{6}\right] \mathrm{Cl}_{3}$ and $1 \mathrm{mM}$ catechol in $100 \mathrm{mM}$ phosphate buffer $\left(\mathrm{KH}_{2} \mathrm{PO}_{4} / \mathrm{K}_{2} \mathrm{HPO}_{4}, \mathrm{pH} 7\right)$ is used for electrochemical measurements. The solution is purged with $\mathrm{Ar}$ for at least $15 \mathrm{~min}$ prior DCV is conducted, and additionally kept under Ar atmosphere during experiments. All chemicals are obtained from Sigma-Aldrich.

\section{Methods}

All potentials reported here are measured versus a $\mathrm{Ag} / \mathrm{AgCl}$ (saturated $\mathrm{KCl}$ ) reference electrode (Radiometer Analytical), and a platinum counter electrode is utilized. For electrochemical measurements a bipotentiostat is used (BioLogic SAS). Each channel is programmed by using conventional $\mathrm{CV}$, however with a fixed potential offset between the two channels. Both channels are started synchronously using standard options in the control software of the bipotentiostat.

\section{RESULTS AND DISCUSSION}

\section{A. FEM model results}

The simulated results are shown in figure 4 . The current contribution of the first redox couple (sp1, $E^{0}=-0.16 \mathrm{~V}$, $\left.\mathrm{C}^{*}=4 \mathrm{mM}\right)$ is indicated in red, and the current contribution of the second redox couple $\left(\mathrm{sp} 2, \mathrm{E}^{0}=0.2 \mathrm{~V}, \mathrm{C}^{*}=1 \mathrm{mM}\right)$ in green. The total current is illustrated in blue. Note that due to the two dimensional nature of the FEM model the current has $\mathrm{A} / \mathrm{m}$ as a unit. Two peaks are clearly visible at the position of the two standard potentials of both redox couples. The peak currents of the first and second couple are $10 \mu \mathrm{A} / \mathrm{m}$ and $4.1 \mu \mathrm{A} / \mathrm{m}$, respectively, thus the ratio between both peak currents is 2.4 . 


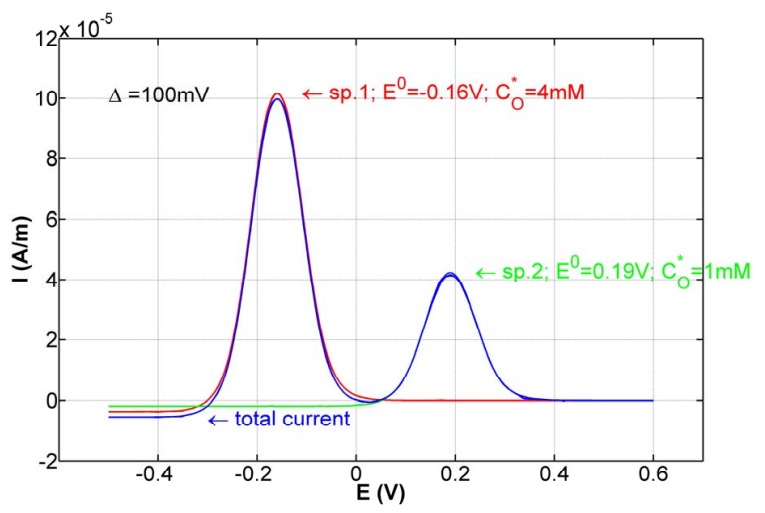

Figure 4. Simulation result of two reversible redox couples (sp.1 and $\mathrm{sp} .2$ ) with a scan rate of $50 \mathrm{mV} / \mathrm{s}$ and a potential difference of $100 \mathrm{mV}$. The peaks clearly indicate the standard potentials of the two redox couples. The peak height can be related to the intial concentrations of both redox couples.

The expected peak ratio is 2 since catechol has a 4 times lower concentration but a two times higher contribution to the current due to a two-electron transfer. The slightly different ratio is caused by the difference in rate constants between couple 1 and 2 . The rate constants used for the simulations are aimed to be close to the actual rate constants of $\mathrm{Ru}\left(\mathrm{NH}_{3}\right)_{6}$ and catechol, which differ approximately by one order of magnitude as indicated in table 1 .

\section{B. Experimental results}

In figure 5 the experimental result of a DCV measurement is shown. In this measurement two peaks can be observed at $-0.17 \mathrm{~V}$ and $0.19 \mathrm{~V}$ corresponding to the standard potentials of $\left[\mathrm{Ru}\left(\mathrm{NH}_{3}\right)_{6}\right] \mathrm{Cl}_{3}$ and catechol, respectively $[5,27]$. The peak height is determined by compensating for the baseline drift using the red line illustrated in figure 5. Using this compensation the peak heights are determined to be $2.29 \mu \mathrm{A}$ and $0.54 \mu \mathrm{A}$ for the left and right peak, respectively. Therefore, the ratio between the peaks is 4.2 .

\section{Model and experimental agreement}

Comparing the results from simulated and experimental data we observe that the ratio of peak heights is slightly different in both cases. We believe this to be caused by adsorption of catechol to the gold surface during the experiments. Also, if the results from the theoretical model are multiplied with the length and amount of finger pairs of the IDE sensor, the resulting peak heights become $2.28 \mu \mathrm{A}$ and $0.91 \mu \mathrm{A}$. Especially the value of the $\mathrm{Ru}\left(\mathrm{NH}_{3}\right)_{6}$ is in fair agreement with experimentally obtained values.

\section{CONCLUSION}

We propose a novel electrochemical measurement technique based on redox cycling, which can be used for selective and simultaneous measurements in mixtures of multiple reversible redox couples. This technique which we have named DCV is based on recording two cyclic voltammograms with a small potential offset. CV is performed at two electrodes placed in close proximity for achievement of sufficient redox cycling amplification. Current amplification

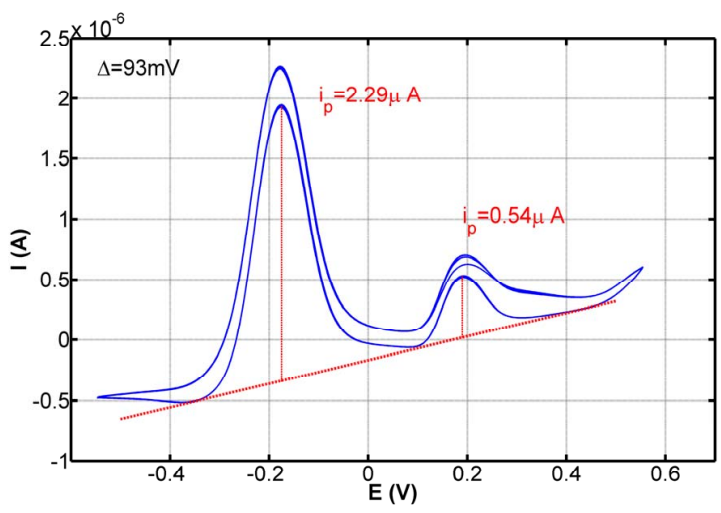

Figure 5. DCV measurement in a mixture of $4 \mathrm{mM}\left[\mathrm{Ru}\left(\mathrm{NH}_{3}\right)_{6}\right] \mathrm{Cl}_{3}, 1 \mathrm{mM}$ catechol and $100 \mathrm{mM}$ phosphate buffer ( $\mathrm{pH} 7$ ) using a $\mathrm{Ag} / \mathrm{AgCl}$ reference electrode (saturated $\mathrm{KCl}$ ), a potential difference of $100 \mathrm{mV}$, and a scan rate of $50 \mathrm{mV} / \mathrm{s}$.

only occurs if one electrode is at a reducing potential while the other electrode is at an oxidizing potential for a specific reversible redox couple. As such, a strong increase in current is only observed if the potentials of both electrodes are surrounding the standard potential of a reversible redox couple. Therefore, the obtained data is comparable to the results obtained with differential pulse voltammetry (DPV). Compared to DPV, DCV has the added benefit of more selectivity even in the presence of high amounts of interfering non-reversible redox active species.

We have developed a finite element model to test this technique and compared theoretical with experimental results. The model and experimental results are in good agreement illustrating the usability of this novel technique. Using DCV we have determined standard potentials and concentrations in a mixture of $4 \mathrm{mM}\left[\mathrm{Ru}\left(\mathrm{NH}_{3}\right)_{6}\right] \mathrm{Cl}_{3}$ and $1 \mathrm{mM}$ catechol simultaneously.

Future work will be focused towards sensors showing higher redox cycling amplification and measurements in solutions containing high concentrations of interfering compounds like ascorbic acid.

\section{ACKNOWLEDGMENT}

The authors would like to thank Johan Bomer for assistance during sensor fabrication.

\section{REFERENCES}

[1] M. Odijk, W. Olthuis, V. Dam, and A. van den Berg, "Simulation of redox-cycling phenomena at interdigitated array (ida) electrodes: Amplification and selectivity," Electroanalysis, vol. 20, no. 5, pp. 463468, 2008.

[2] V. A. T. Dam, W. Olthuis, and A. van den Berg, "Redox cycling with facing interdigitated array electrodes as a method for selective detection of redox species," The Analyst, vol. 1, p. 1, 2007, dOI: $10.1039 / \mathrm{b} 616667 \mathrm{a}$.

[3] M. Morita, O. Niwa, and T. Horiuchi, "Interdigitated array microelectrodes as electrochemical sensors," Electrochemica Acta, vol. 42, no. 20-22, pp. 3177-3183, 1997.

[4] K. Hayashi, Y. Iwasaki, R. Kurita, K. Sunagawa, and O. Niwa, "Online microfluidic sensor integrated with a micro array electrode and 
enzyme-modified pre-reactor for the real-time monitoring of blood catecholamine," Electrochemistry Communications, vol. 5, pp. 1037 1042, 2003.

[5] B. Wolfrum, M. Zevenbergen, and S. Lemay, "Nanofluidic redox cycling amplification for the selective detection of catechol," Anal. Chem., vol. 80, pp. 972-977, 2008.

[6] F.-R. F. Fan and A. J. Bard, "Electrochemical detection of single molecules," Science, vol. 267, no. 5199, pp. 871-874, 1995.

[7] A. J. Bard and L. R. Faulkner, Electrochemical methods - fundamentals and applications, 2nd ed., E. Swain, Ed. Wiley, 2001.

[8] D. G. Sanderson and L. B. Anderson, "Filar electrodes: Steady-state currents and spectroelectrochemistry at twin interdigitated electrodes," Analytical Chemistry, vol. 57, pp. 2388-2393, 1985.

[9] A. J. Bard, J. A. Crayston, G. P. Kittlesen, T. V. Shea, and M. S. Wrighton, "Digital simulation of the measured electrochemical response of reversible redox couples at microelectrode arrays: Consequences arising from closely spaced ultramicroelectrodes," Analytical Chemistry, vol. 58, pp. 2321-2331, 1986.

[10] B. Seddon, H. Girault, and M. Eddowes, "Interdigitated microband electrodes: chronoamperometry and steady state currents," Journal of Electroanalytical Chemistry, vol. 266, pp. 227-238, 1989.

[11] Y. Iwasaki and M. Morita, "Electrochemical measurements with interdigitated array microelectrodes," Current separations, vol. 14, pp. $1-8,1995$.

[12] P. Jin, A. Yamaguchi, F. A. Oi, shigeki Matsuo, J. Tan, and H. Misawa, "Glucose sensing based on interdigitated array microelectrode," Analytical sciences, vol. 17, pp. 841-846, 2001.

[13] J. Min and A. J. Baeumner, "Characterization and optimization of interdigitated ultramicroelectrode arrays as electrochemical biosensor transducers," Electroanalysis, vol. 16, no. 9, pp. 724-729, 2004.

[14] O. Niwa, M. Morita, and H. Tabei, "Electrochemical behavior of reversible redox species at interdigitated array electrodes with different geometries: Consideration of redox cycling and collection efficiency," Analytical Chemistry, vol. 62, pp. 447-452, 1990.

[15] O. Niwa, H. Tabei, B. P. Solomon, F. Xie, and P. T. Kissinger, "Improved detection limit for catecholamines using liquid chromatography-electrochemistry with a carbon interdigitated array microelectrode," Journal of Chromatography B, vol. 1, pp. 21-28, 1995.

[16] M. Paeschke, U. Wollenberger, C. Kohler, T. Lisec, U. Schnakenberg, and R. Hintsche, "Properties of interdigital electrode arrays with different geometries," Analytica Chimica Acta, vol. 305, pp. 126-136, 1995.
[17] X. Yang and G. Zhang, "Diffusion-controlled redox cycling at nanoscale interdigitated electrodes," Comsol Proceedings and user presentations $C D$, vol. 1, pp. 1-6, 2005.

[18] F. Bjorefors, C. Strandman, and L. Nyholm, "Electrochemical detection based on redox cycling using interdigitated microarray electrodes at ul/min flow rates," Electroanalysis, vol. 12-4, pp. 255-261, 2000.

[19] K. Hayashi, Y. Iwasaki, R. Kurita, K. Sunagawa, O. Niwa, and A. Tate, "The highly sensitive detection of catecholamines using a microfluidic device integrated with an enzyme-modified pre-reactor for interferent elimination and an interdigitated array electrode," Journal of Electroanalytical Chemistry, vol. 579, pp. 215-222, 2005.

[20] R. Kurita, H. Tabei, Z. Liu, T. Horiuchi, and O. Niwa, "Fabrication and electrochemical properties of an interdigitated array electrode in a microfabricated wall-jet cell," Sensors and actuators B, vol. 71, pp. 8289, 2000.

[21] H. Tabei, M. Takahashi, S. Hoshino, O. Niwa, and T. Horiuchi, "Subfemtomole detection of catecholamine with interdigitated array carbon microelectrodes in hplc," Analytical Chemistry, vol. 66, no. 20, pp. 3500-3502, 1994.

[22] K. Ueno, H. Kim, and N. Kitamura, "Characteristic electrochemical responses of polymer microchannel-microelectrode chips," Analytical Chemistry, vol. 75, no. 9, pp. 2086-2091, 2003.

[23] E. D. Goluch, B. Wolfrum, P. S. Singh, M. A. G. Zevenbergen, and S. G. Lemay, "Redox cycling in nanofluidic channels using interdigitated electrodes," Anal Chem, vol. 394, pp. 447-456, 2009.

[24] M. Zevenbergen, D. Krapf, M. Zuiddam, and S. Lemay, "Mesoscopic concentration fluctuations in a fluidic nanocavity detected by redox cycling," Nano Lett., vol. 7, no. 2, pp. 384-388, 2007.

[25] J. Wiedemair, N. Menegazzo, J. Pikarsky, K. S. Booksh, B. Mizaikoff, and C. Kranz, "Novel electrode materials based on ion beam induced deposition of platinum carbon composites," Electrochimica Acta, vol. 55, pp. 5725-5732, 2010.

[26] R. de Cassia Silva Luz, F. S. Damos, A. B. de Oliveira, J. Beck, and L. T. Kubota, "Development of a voltammetric sensor for catechol in nanomolar levels using a modified electrode with cu(phen)2(tcnq)2 and pll," Sensors and Actuators B, vol. 117, pp. 274-281, 2006.

[27] D. E. Khoshtariya, T. D. Dolidze, A. Vertova, M. Longhi, and S. Rondinini, "The solvent friction mechanism for outer-sphere electron exchange at bare metal electrodes. the case of au/ru(nh3)6 redox system," Electrochistry Communications, vol. 5, pp. 241-245, 2003.

[28] M. R. Deakin, P. M. Kovach, K. J. Stutts, and R. M. Wightman, "Heterogeneous mechanisms of the oxidation of catechols and ascorbic acid at carbon electrodes," Anal Chem, vol. 58, pp. 1474-1480, 1986. 